\title{
RELATIONSHIP BETWEEN EMOTIONAL INTELLIGENCE AND ORGANIZATIONAL CITIZENSHIP BEHAVIOR IN CRITICAL AND EMERGENCY NURSES IN SOUTH EAST OF IRAN
}

\author{
Tofighi $\mathbf{M}^{1}$, Tirgari $\mathbf{B}^{2}$, Fooladvandi $\mathbf{M}^{1}$, Rasouli $\mathbf{F}^{1}$, Jalali $\mathbf{M}^{3}$
}

\begin{abstract}
BACKGROUND: Several factors including emotional intelligence affect the efficiency of people. It seems that organizational behavior of each person is strongly influenced by emotional intelligence. Therefore, the present study is aimed to examine the relationship between emotional intelligence and organizational citizenship behavior in critical and emergency nurses in teaching hospitals supervised by Kerman Medical University in Southeast of Iran.

METHODS: This study employed a descriptive cross sectional design. A census sample consisted of 150 critical and emergency nurses working in teaching hospitals supervised by Kerman Medical University participated in this study. Emotional intelligence and organizational citizenship behavior questionnaire was used to assess nurses' emotional intelligence and organizational citizenship behavior by available sampling method.

RESULTS: The results showed that the mean age of the participants was 35 years. Most participants (94\%) were females and belonged to the age group of 26-30 years. Overall mean score of organizational citizenship behavior scale was $88.21( \pm 10.4)$. In the organizational citizenship behavior categories, altruism mean score was higher than the other mean scores. Overall mean score of emotional intelligence was $(121.08 \pm 17.56)$. In the subgroups of emotional intelligence, mean score of the relationship management, was higher than the average of other factors. Pearson's correlation coefficient showed no significant relationship between emotional intelligence and organizational citizenship behavior $(p \geq 0.05)$.

CONCLUSIONS: The study suggests that health care managers should organize systematic and dynamic policies and procedures in dealing with emotional intelligence and organizational citizenship behavior to assist critical and emergency nurses.

KEYWORDS: Emotional intelligence, Oorganizational citizenship behavior, nurse, critical ward, emergency ward
\end{abstract}

DOI: http://dx.doi.org/10.4314/ejhs.v25i1.11

\section{INTRODUCTION}

Several factors including emotional intelligence affect the efficiency of people. Organizational behavior of each person is also strongly influenced by emotional intelligence. Mayer, DiPaolo and Salovey (1990) introduced emotional intelligence as a set of social skills and abilities, distinct from rational intelligence (1). In the early 1990, the term emotional intelligence in the Mayer and Salovey's scientific literature is defined as the subgroup of social intelligence. That is including study of the feelings and emotions to distinguish between them, and the use of this information to

\footnotetext{
${ }^{1}$ School of Nursing and Midwifery, Kerman University of Medical Sciences, Kerman, Iran

${ }^{2}$ Neuroscience Research Center, Institute of Neuropharmacology, Kerman University of Medical Sciences, Kerman, Iran

${ }^{3}$ School of Nursing and Midwifery, Esfahan University of Medical Silences, Esfahan, Iran

Corresponding Author: Foolavandi Masoomeh, Email: sfuladvand@yahoo.com
} 
guide reasoning and action (2). Salovey and Mayer (1990) introduced the concept of emotional intelligence as a set of abilities, in relation to emotions and emotional information processing (3). They defined it as a form of social reaction that includes perception, analysis and construction of specific behaviors for emotional content. The people who have the evolved emotional intelligence, in general, are more aware of their personal emotions, and can control and express it. It also has been shown that people with high emotional intelligence are more willing to have positive relationships with others, but less willing to have a negative interaction with close friends (4). Mayer and Salovey have divided the concept of emotional intelligence, in general, the four dimensions, although other models such as the five-component model of Bar-owen's are generally accepted. George (2000) and others (eg, Mayer, Salovey and Caruso, 1999) expressed the four dimensions of emotional intelligence hypothesized by Mayer and Salovey, as briefly as: understanding of emotions, integrity of emotions, knowledge about emotion, and emotion control (5). Mayer and Salovey (1995), defined emotional intelligence as the ability to process emotional information with more precisely and efficiently, including information relating to the identification, construction and adjustment of emotions in self and others. Dimensions of emotional intelligence include self-confidence, self-control, emotional awareness and empathy (6). Mayer and Salovey (1997) suggested four components for emotional intelligence which include knowledge, understanding, adjustment, and general intelligence (7). They defined the term as social skills including understanding and appropriate expression of emotions, emotions matched with future cognitive processes, understanding of emotions and their concepts for different situations and emotions managing (8). According to Boyatzis et al., (2002) emotional intelligence includes a set of emotions, social knowledge, and abilities that guides and strengthens our overall strength in the direction that we appropriately are able to respond to environmental factors and pressures, causing can improved performance in four areas, self-awareness (the understand to own abilities and express them), social awareness (knowledge than others, and understanding one's abilities, and empathy), relationship management, and self-management (ability to adapt whit changes and solve personal and social problems) (9). One of the important factors that can lead to improvement of the quality of the behaviors, attitudes, and interactions of employees is organizational citizenship behavior (OCB). Organizational citizenship behavior is a set of voluntary behaviors, which does not count as the official duties of the person, but are done by them, and could lead to improved efficiency of tasks and organization roles (10). This term is defined with words such as good soldiers, arbitrary behavior, voluntary behavior, and the exit of the task behavior, which created a new movement in the organization vision, especially in the field of organizational behavior, which has a critical role in organizational efficiency (11). Batman and Organ (1983) presented the concept of organizational citizenship behavior to the world of science (12). They defined the term organizational citizenship behavior as off-duty activities of employees, which enhance the efficiency of the organization (13). Graham (1991) believed that organizations have the three OCB include organizational obedience, organizational loyalty and organizational participation (12).

Organizational citizenship behavior is a cautionary unique behavior, which directly or explicitly, is not recognized by the formal reward system; in total, it enhances the effective performance of the organization (14). Podsakoff et al (2000) designed a theoretical five-factor model which explains OCB including altruism (helping behaviors for supporting of personnel or the coworkers who have work associated problems), conscientiousness (behavior that causes a person y to do more than what he is expected), courtesy (courteous manners which avoids creation of problem at workplace), sportsmanship (fair behaviors that avoid too much complaint at work) and civic virtue (it expresses behaviors of individual involvement in the activities related to the organization) (15).

Willard (2006) assessed the relationship between emotional intelligence and adherence to combination antiretroviral medications in individuals living with HIV disease. They reported no significant relationship between the overall score, or the score of each factor of emotional Intelligence with the dependence on new drugscombined consumption by patients with HIV (16). 
Refler (2004) examined the impact of the leader's emotional intelligence on employees' trust in their leader and employee-organizational citizenship. They concluded that managers who had high emotional intelligence had staff who showed high OCB (17). In a correlation study, Korkmaz and Arpac (2009) assessed the relationship between organizational citizenship behavior and emotional intelligence among 114 staff of Istanbul industries. They concluded that the emotional intelligence has a positive correlation with two components of organizational citizenship behaviors (consciousness and altruism). They stressed that emotional intelligence is an important factor for the effective leader. The leader's emotional intelligence will be affected by the followers' OCB. (18). Aghdasi and Kiamanesh (2011) also found that only occupational stress has a negative indirect effect on organizational commitment and job satisfaction (19). In a study on more than 200 employees in private companies, Guangling (2011) found that the sense of organizational justice has a positive predictive role on organizational identification. According to them, organizational justice definitely identifies the organization enhancement and organizational citizenship behavior. They explained that the organizational recognition plays the mediator role in the relationship between organizational justice and organizational citizenship behavior (20). In northern India, Jain and Cary (2012) reported a negative relationship between stress and organizational citizenship behavior. The results showed that stress has a significant negative effect on organizational citizenship behavior (21). Barriball et al (2011) assessed relationships between emotional intelligence and stress, coping, well-being and professional performance in nursing. They concluded that emotional intelligence is negatively correlated with wellbeing, coping with problems, perceived nursing competence, and perceived stress (22). In Iran, Jafari and Bidarian (2012) examined the relationship between organizational citizenship behavior and organizational justice in science and research campus employees. They established the significant positive correlation between components of organizational justice and organizational citizenship behavior (23).

Nurses, as part of manpower in health care organizations, are faced with many conflicts.
Professional manner in these situations, emotional intelligence and mental health may lead them to good citizenship behavior. In other words, organization is one of the indicators that lead to improved employee performance. It may lead to the organizational citizenship behavior towards achieving its goals. Recognizing the relationship of these variables can have positive results in enterprise environments including hospitals, and leads to job development and quality of service. Few studies in the field of emotional intelligence and its relationship with $\mathrm{OCB}$ in nurses were conducted in Iran. However, the association between these two variables in nurses was ignored. Therefore, the present study is aimed to examine the relationship between emotional intelligence and organizational citizenship behavior in critical and emergency nurses in teaching hospitals supervised by Kerman Medical University in southeast of Iran.

\section{MATERIALS AND METHODS}

Design: This study employed a descriptive cross sectional design. Based on the calculated sample size, a convenience sample consisting of 150 critical and emergency nurses participated in this study.

Instruments: Data were collected using the demographic questionnaire consisting of emotional intelligence and organizational citizenship behavior scales. Demographic questionnaire assessed such data as participants' as age, gender, experience, education, organizational unit, and so on. Emotional intelligence was measured by the BradburyGraves's emotional intelligence Inventory (2005). This questionnaire consists of 23 items categorized in four subscales: self-awareness (items 1 to 6), self-management (items 7-13), social awareness (items 14 of 20), and relationship management (items 21-28). Emotional intelligence score was the sum of these four sub-groups and ranged between 94 and 160. The highest possible total score was 115 with higher scores indicating a greater level of emotional intelligence. In a 6-point Likert type scale, responses ranged from 1 (Never) to 6 (Always). Reliability and Validity of the questionnaire was approved by Ganji (2006) in Iran. It was considered reliable $(\alpha$ Chronbach=0.90) and valid measure (24). 
To assess participants' organizational citizenship behavior, the OCB (organizational citizenship behavior) questionnaire (Podsakoff, 2008) was used. This consisted of 24 items. The response rate ranged between 1 and 5 (1= disagree; $5=$ agree $)$. It is divided into five components; conscientiousness (5 items), Sportsmanship (5 questions), courtesy (5 items), Civic virtue (4 items), Altruism (5 items) (15).

The overall OCB score was computed by summing responses to all 24 items. The range was between 24 and 120. Higher scores reflected a higher degree of OCB. In the Iranian context, this questionnaire was translated and used by Hoveida and Naderi in 2009. They reported that the reliability of the scale was 0.89 and that it had an acceptable content validity (25).

Data collection and analysis: The questionnaire was accompanied by a letter including some information about the aim of the study which was handed out by the third author to 150 critical and emergency nurses who had worked in teaching hospitals, supervised by the Kerman Medical University in southeast of Iran.

Confidentiality was kept by making participation. Data from the questionnaire were analyzed using the Statistical Package for the Social Sciences (SPSS). Descriptive analysis was made to determine the characteristics of the sample. A Kolmogorov-Smirnov test was conducted to indicate that the data were sampled from a population with normal distribution. This test indicated that the data were sampled from a population with normal distribution. Therefore, the correlation between emotional intelligence and organizational citizenship behavior scores was examined by the Pearson correlation coefficient. To compare emotional intelligence and OCB scores according to demographic factors (gender, level of experience, education, organizational units), one-way ANOVA and independent T-test was used. The significance level was set to $\mathrm{P}<$ 0.05 .

\section{RESULTS}

Descriptive Findings: A descriptive analysis of background information revealed that the mean age of the participants was 35 years. Most participants $(94 \%)$ were females. Most of the participants belonged to the age group of 26-30 years. Most of samples (88\%) had Bachelor's degree. Fifty-three percent had a work experience between 2 to 9 years; most of them (39.3\%) worked in the ICU (Table 1).

Table1: Participants demographic characteristics

\begin{tabular}{lccc}
\hline Variable & & Frequency & Percent \\
\hline Age(years) & $20-25$ & 25 & 16.7 \\
& $26-30$ & 45 & 30.00 \\
& $31-35$ & 43 & 28.7 \\
& $36-40$ & 19 & 12.17 \\
Gender & $41-45$ & 13 & $8 / 7$ \\
& $46-50$ & 5 & $3 / 3$ \\
Education & Male & 9 & 6 \\
& Female & 141 & 94.00 \\
& Diploma & 13 & 8.7 \\
Work & Associate Degree & 2 & 1.3 \\
Experience & Bachelor Degree & 132 & 88 \\
& master Degree & 3 & 2 \\
& $2-9$ & 83 & 55.3 \\
Organizational & $10-17$ & 38 & 25.3 \\
unit & $18-25$ & 26 & 17.3 \\
& $26-32$ & 3 & 2 \\
& Emergency & 43 & 28.7 \\
& ICU & 59 & 39.3 \\
& CCU & 35 & 23.3 \\
\hline
\end{tabular}


The mean score of organizational citizenship behavior was $88.21( \pm 10.54)$. The mean score of OCB components were conscientiousness 20.96 ( \pm 2.58), sportsmanship $11.77( \pm 4.53)$, politeness and respect $14.82( \pm 5.40)$, civic virtue $19.86( \pm 1.87)$ and altruism is $38.48( \pm 3.63)$ respectively. The maximum mean score belonged to the altruism category (Table 2).

\section{Table 2: OCB and EI scores}

\begin{tabular}{|c|c|c|c|}
\hline Scale & Scale items & Mean & SD \\
\hline \multirow{16}{*}{$\begin{array}{c}\text { OCB } \\
\text { categories }\end{array}$} & OCB & 88.21 & 10.54 \\
\hline & Conscientiousness & 20.96 & 2.58 \\
\hline & I' m helping to employees who have been absent. & 4.68 & 0.88 \\
\hline & $\begin{array}{l}\text { I spent a lot of time for complaining about trivial } \\
\text { problems }\end{array}$ & 1.96 & 1.25 \\
\hline & Sportsmanship & 11.77 & 4.53 \\
\hline & I like to make a mountain of a straw. & 3.10 & 1.45 \\
\hline & I do not create unnecessary interruptions in the work. & 1.80 & 1.19 \\
\hline & Courtesy & 14.82 & 5.40 \\
\hline & I do not abuse of the rights of others. & 4.84 & 4.64 \\
\hline & $\begin{array}{l}\text { I most emphasize on the negative aspects of owns } \\
\text { work to the positive aspects of it. }\end{array}$ & 3.22 & 1.37 \\
\hline & Civic virtue & 19.86 & 1.87 \\
\hline & $\begin{array}{l}\text { Notes, announcements and... of the organization read } \\
\text { and would be protected it. }\end{array}$ & 4.79 & 0.58 \\
\hline & Often in what the organization is doing, I find flaws. & 1.52 & $\mathbf{1 . 1 0}$ \\
\hline & altruism & 38.48 & 3.63 \\
\hline & $\begin{array}{l}\text { I'm squeak wheels often require greasing as a perfect } \\
\text { example. }\end{array}$ & 4.78 & 3.33 \\
\hline & $\begin{array}{l}\text { I will consider Influence the actions of their } \\
\text { colleagues. }\end{array}$ & 4.46 & 0.66 \\
\hline \multirow{13}{*}{ EI categories } & EI & 12.08 & $\mathbf{1 7 . 5 6}$ \\
\hline & Self-awareness & 26.73 & 4.55 \\
\hline & You have confidence in your abilities. & 4.80 & 1.00 \\
\hline & Hardships that you face, you have a role. & 3.93 & 1.22 \\
\hline & Self-management & 28.51 & 5.35 \\
\hline & Can be counted on you. & 4.76 & 1.05 \\
\hline & you tolerate disappointment without discomfort & 3.32 & 1.43 \\
\hline & Social awareness & 30.4 & 4.31 \\
\hline & You understand the feelings of others. & 4.56 & 1.01 \\
\hline & When you get upset do things regret you later. & 3.96 & 1.26 \\
\hline & relationship management & 35.80 & $9-06$ \\
\hline & $\begin{array}{l}\text { You Show others that what you feeling, it is important } \\
\text { to you. }\end{array}$ & 5.00 & 5.11 \\
\hline & You directly face with others in difficult situations. & 3.70 & 1.31 \\
\hline
\end{tabular}

OCB: Organizational citizenship behavior,

OCB score grouped into three categories included low (55 to 24$)$, moderate $(56,87)$ and high $(88,120)$. More than half of the participants $(52 \%)$ had average organizational citizenship behavior,

EI: Emotional Intelligence

and $48 \%$ t belonged to the high category of organizational citizenship behavior (Table 3). 
Table 3: OCB Scores

\begin{tabular}{ccc}
\hline OCB score & OCB level & percent \\
\hline $88-120$ & High & $52 \%$ \\
$56-87$ & Average & $48 \%$ \\
$24-55$ & Low & $0 \%$ \\
\hline
\end{tabular}

OCB: Organizational citizenship behavior

Total mean score of emotional intelligence was $121.08( \pm 17.56)$. The mean scores of emotional intelligence components were respectively selfawareness $=26.73( \pm 4.55)$, self-management $=$ $28.51( \pm 5.35)$, social awareness $=30.04( \pm 4.31)$ and management of relationships $35.80=( \pm 9.06)$. Therefore, the highest mean score belonged to the management of relationships category (Table 2). Also, emotional intelligence categorized into three groups included low ( 28 to 74 ), moderate ( 75 to 121 ) and high (122 to 168 ). About $43.3 \%$ of participants were in high category of emotional intelligence, while $55.3 \%$ were in the moderate group and 1.3 percent belongs to the low group (Table 4).

Table 4: EI Scores

\begin{tabular}{llc}
\hline EI score & EI level & percent \\
\hline $122-168$ & High & $43.3 \%$ \\
$75-121$ & Average & $55.3 \%$ \\
$28-74$ & Low & $1.3 \%$ \\
\hline
\end{tabular}

EI: Emotional Intelligence

Correlations between emotional intelligence and OCB scores: A significant positive correlation was found between the mean score of OCB and all category of emotional intelligence ( $p$
$<$ 0.001). Also Pearson correlation coefficient showed a significant positive correlation between the conscientiousness category of OCB with selfmanagement $(\mathrm{p}<0.001)$, social awareness ( $\mathrm{p}$ $<0.05$ ), and management of relationships ( $<0.001$ ) categories of emotional intelligence respectively (Table 5).

There was a significant positive correlation between sportsmanship category of OCB and selfawareness $(p<0.05)$ and self-management $(p<$ 0.001 ) categories of emotional intelligence. A significant positive correlation was also found between the mean scores of civic virtue category and OCB and self-management $(\mathrm{p}<0.05)$. According to the Pearson correlation coefficient, a significant positive relationship was found between courtesy category of OCB and selfmanagement ( $\mathrm{p}<0.001)$, social awareness $(\mathrm{p}<$ $0.05)$ and management of relationships $(\mathrm{p}<0.05)$. A significant positive relationship was also observed between altruism category of OCB and self-awareness categories of emotional intelligence $(\mathrm{p}<0.05)$ (Table 5).

Pearson correlation coefficient showed no a significant relationship between emotional intelligence and OCB total scores $(\mathrm{p} \geq 0.05)$. A significant correlation was found between total score of emotional intelligence and organizational citizenship behavior subscales (conscientiousness $(\mathrm{p}<0.001)$, courtesy and respect $(\mathrm{p}<0.001)$ and altruism $(\mathrm{p}<0.05)$. There was a significant negative relationship between sportsmanship category of organizational citizenship behavior and total emotional intelligence $(\mathrm{p}<0.05)$ (Table $5)$.

Table 5: Relationship between EI and OCB

\begin{tabular}{lcccccc}
\hline & OCB (overall) & Civic virtue & Sportsmanship & altruism & Courtesy & Conscientiousness \\
\hline EI (overall) & $\mathrm{R}=0.137$ & $\mathrm{R}=0.133$ & $\mathrm{R}=-0.170$ & $\mathrm{R}=0.603$ & $\mathrm{R}=0.236$ & $\mathrm{R}=0.273$ \\
& $\mathrm{P}=0.095$ & $\mathrm{P}=0.105$ & $\mathrm{P}=0.037^{*}$ & $\mathrm{P}=0.00^{* *}$ & $\mathrm{P}=0.004^{*}$ & $\mathrm{P}=0.001^{* *}$ \\
\hline
\end{tabular}

OCB: Organizational citizenship behavior, EI: Emotional Intelligence, *Pearson correlation is significant at the level of $\mathrm{p} \leq 0.05 *$ and $\mathrm{p} \leq 0.001 * * *$

\section{Correlations between emotional intelligence and OCB scores with demographic information}

According to the one-way ANOVA test, a significant correlation was found between selfmanagement category of emotional intelligence and age groups $(\mathrm{p}=0.04)$ and work experiences $(\mathrm{p}=0.002)$ respectively. One-way ANOVA test also revealed a correlation between civic virtue category of OCB and education $(\mathrm{p}=0.003)$ (Table $6)$. 
Table 6: relationship of demographic variables with OCB and EI Scores

\begin{tabular}{lccccc}
\hline & $\begin{array}{c}\text { Age groups } \\
\text { One -way } \\
\text { ANOVA / p- } \\
\text { value }\end{array}$ & $\begin{array}{c}\text { Education } \\
\text { One -way } \\
\text { ANOVA / }- \\
\text { value }\end{array}$ & $\begin{array}{c}\text { Work } \\
\text { Experience } \\
\text { One -way } \\
\text { ANOVA / p- } \\
\text { value }\end{array}$ & $\begin{array}{c}\text { Organizational } \\
\text { unit } \\
\text { One -way } \\
\text { ANOVA / p- } \\
\text { value }\end{array}$ & $\begin{array}{c}\text { Gender } \\
\text { Independent - } \\
\text { samples T } \\
\text { Test / p-value }\end{array}$ \\
\hline OCB & $\mathrm{P}=0.52$ & $\mathrm{P}=0.41$ & $\mathrm{P}=0.63$ & $\mathrm{P}=0.39$ & $\mathrm{P}=0.66$ \\
Conscientiousness & $\mathrm{P}=0.1$ & $\mathrm{P}=0.84$ & $\mathrm{P}=0.18$ & $\mathrm{P}=0.06$ & $\mathrm{P}=0.95$ \\
Sportsmanship & $\mathrm{P}=0.23$ & $\mathrm{P}=0.51$ & $\mathrm{P}=0.95$ & $\mathrm{P}=0.84$ & $\mathrm{P}=0.77$ \\
Courtesy & $\mathrm{P}=0.69$ & $\mathrm{P}=0.77$ & $\mathrm{P}=0.71$ & $\mathrm{P}=0.16$ & $\mathrm{P}=0.9$ \\
Civic virtue & $\mathrm{P}=0.19$ & $\mathbf{P}=\mathbf{0 . 0 0 3}$ & $\mathrm{P}=0.23$ & $\mathrm{P}=0.76$ & $\mathrm{P}=0.3$ \\
altruism & $\mathrm{P}=0.66$ & $\mathrm{P}=0.5$ & $\mathrm{P}=0.63$ & $\mathrm{P}=0.81$ & $\mathrm{P}=0.59$ \\
EI & $\mathrm{P}=0.18$ & $\mathrm{P}=0.61$ & $\mathrm{P}=0.09$ & $\mathrm{P}=0.83$ & $\mathrm{P}=0.25$ \\
self-awareness & $\mathrm{P}=\mathbf{0 . 0 8}$ & $\mathrm{P}=0.26$ & $\mathrm{P}=0.16$ & $\mathrm{P}=0.62$ & $\mathrm{P}=0.062$ \\
self-management & $\mathbf{P}=\mathbf{0 . 0 4} *$ & $\mathrm{P}=0.61$ & $\mathbf{P}=\mathbf{0 . 0 2} *$ & $\mathrm{P}=0.74$ & $\mathrm{P}=0.22$ \\
social awareness & $\mathrm{P}=0.05$ & $\mathrm{P}=0.48$ & $\mathrm{P}=0.07$ & $\mathrm{P}=0.52$ & $\mathrm{P}=0.47$ \\
relationship management & $\mathrm{P}=0.9$ & $\mathrm{P}=0.68$ & $\mathrm{P}=0.68$ & $\mathrm{P}=0.97$ & $\mathrm{P}=0.96$ \\
\hline
\end{tabular}

OCB: Organizational citizenship behavior, EI: Emotional Intelligence, *Pearson correlation is significant at the level of $\mathrm{p} \leq 0.05$

\section{DISCUSSION}

Based on the findings of the present study, the mean score of altruism category of OCB was $38.48( \pm 3.63)$, which was higher than the other categories. This is consistent with the results of Yazdani et al's (2011) and Hajali and Salimi's (2012) studies. They also reported that the average score of altruism is higher than the average of other dimensions $(10,26)$. However, some studies, i.e, Salazhi et al (2011), Korkmaz and Arpac (2009) and Khalesi et al (2009)) found inconsistent results $(27,18$, and 28). In Tehran (Capital of Iran), Khalesi et al (2009) in a study on health care workers of Tehran University of Medical Sciences, showed that the highest mean score belonged to the sortsmanship dimension (27). Salazhi et al (2011) and Korkmaz and Arpac (2009) showed that, mean score of the courtesy category was higher than the other dimensions $(18,28)$. The difference between the findings of this study from studies mentioned above is probably because of differing populations and type of organizational culture.

Nurses are the first people who deal with and are responsible for their patients. They endure their workload. In such circumstances, altruism as an additional treatment for members of the organization in relation problems may be more important.
Mean scores of emotional intelligence subgroups also showed that the highest mean score belonged to the subgroup of relationship management. Researchers have not been able to find consistent findings in this field, but it can be said that a high score in this category is because of the high scores in the self-awareness, self-management and social awareness. In contrast, in Iran, Asadi et al (2011) and Delpasand et al ( 2012) showed inconsistent results $(29,30)$. In a study on a public library staff, Asaadi et al (2011) reported that selfawareness dimension had higher mean score (29). Also, Delpasand et al (2012) reported that the nurses working in intensive care units supervised by the Tehran Social Security obtained higher score in self awareness dimension (30). The contrast in findings could be caused by differences instruments, sample sizes, and characteristics.

According to the findings of this study, there was no significant relationship between overall score of emotional intelligence and OCB. A significant positive correlation was found between organizational citizenship behaviors subscales (conscientiousness, courtesy, respect and altruism) with total score of emotional intelligence. There was significant negative relationship between the average scores of sportsmanship aspects of organizational citizenship behavior and total score of emotional intelligence. However, we did not find a significant relationship between emotional intelligence scores with aspects to civic virtue of 
organizational citizenship behavior. These results are consistent with findings of study conducted by Asadi et al, on public library staff. They reported that there was a significant relationship between emotional intelligence and each of the dimensions of organizational citizenship behavior (30).

Another finding of our study was significant positive correlation between the mean score of OCB with four aspect of emotional intelligence. These findings are consistent with Asaadi et al (2011) study. They also showed that all the four dimensions of emotional intelligence are significantly correlated with organizational citizenship behavior, and the correlation value is also acceptable and appropriate (30).

The result showed a significant positive correlation between conscientiousness category of OCB and three categories of emotional intelligence (self-management, social awareness and relationship management). Another finding was a significant positive correlation between sportsmanship aspects of organizational citizenship behavior and self-awareness, self management. Also, significant positive correlation was found between civic virtue of OCB, with self-management. These results are inconsistent with findings of earlier studies due to use of different questionnaires of organizational citizenship behavior and emotional intelligence $(18,31)$. Researchers have not found similar study, which have examined the relationship between each dimensions of organizational citizenship behavior and aspects of emotional intelligence.

A significant relationship was found between self-management aspects and work experience and age. A similar study was not found. However, Hatamgooya et al (2010), using Bar-owen's emotional intelligence questionnaire, showed that there is no significant relationship between emotional intelligence and demographic characteristics (32). It can be said that, with increasing age and experience and ability to adapt with changes, personal and social problem solving also increase. Results of this study showed a significant relationship between civic virtue and education. It means participants with postgraduate educational level had a higher rate of civic virtue behavior than those with other level of education. A similar study was not found. However, it can be said that, whenever is higher one's level of education, a sense of responsibility towards the organization will grow. Therefore, civic virtue as an expression of behaviors of individuals involving in activities related to the organization goes up.

Our findings indicated that there was a significant relationship between some categories of emotional intelligence and OCB. The results also showed a significant relationship between self-management category of emotional intelligence and work experience and age. Civic virtue category of $\mathrm{OCB}$ also correlated with education. Nurses, as part of manpower in health care organizations and are faced with many conflicts. In these situations, professional manner, high emotional intelligence and mental health may lead to good citizenship behavior in them. Therefore, it is suggested that the health care managers should organize systematic and dynamic policies and procedures to deal with emotional intelligence and organizational citizenship behavior to assist critical and emergency nurses.

Since emotional intelligence questionnaire Bradbury- Graves has been used in a few studies, it is suggested:

1. Further studies should be conducted on the relationship between emotional intelligence and organizational citizenship behavior using of this questionnaire in different nursing communities.

2. Organizational citizenship behavior categories should be used to evaluate the performance of nurses in order to improve the patient care and their relationships with colleagues.

3. A continuing educational program in the field of organizational citizenship behavior and emotional intelligence could be deemed somehow helpful among all hospital staff, faculty and students.

Our study has several limitations. The sample of participants which is not representative of all critical and emergency nurses could deteriorate the generalization of the findings. Use of self-report questionnaire may lead to an overestimation of some of the findings due to variance. Another limitation is limited time that participants had to fill in the questionnaire. To reduce these limitations, the third author asked participants to fill in the questionnaire whenever or wherever they preferred. 


\section{ACKNOWLEDGEMENTS}

The authors wish to thank Kerman University of Medical Science for their kind assistance to the present study. Also, we thank all the nurses participated in current study.

\section{REFERENCES}

1. Jordan PJ, Ashkanasy NM, Härtel CE, Hooper GS. Workgroup emotional intelligence: Scale development and relationship to team process effectiveness and goal focus. Human Resource Management Review, 2002; 12(2):195-214.

2. Beauvais AM, Brady N, O'Shea ER, Griffin MTQ. Emotional intelligence and nursing performance among nursing students. Nurse Education Today. 2011; 31(4):396-401.

3. Côté S, Lopes PN, Salovey P, Miners CT. Emotional intelligence and leadership emergence in small groups. The Leadership Quarterly. 2010; 21(3):496-508.

4. Lomas J, Stough C, Hansen K, Downey LA. Brief report: Emotional intelligence, victimisation and bullying in adolescents. Journal of adolescence. 2012; 35(1):207-11.

5. Van Rooy DL, Viswesvaran C. Emotional intelligence: A meta-analytic investigation of predictive validity and nomological net. Journal of Vocational Behavior. 2004; 65(1):71-95.

6. Quebbeman AJ, Rozell EJ. Emotional intelligence and dispositional affectivity as moderators of workplace aggression: The impact on behavior choice. Human Resource Management Review. 2002; 12(1):125-43.

7. Scott-Ladd B, Chan CC. Emotional intelligence and participation in decision-making: strategies for promoting organizational learning and change. Strategic Change. 2004; 13(2):95-105.

8. Lyons JB, Schneider TR. The influence of emotional intelligence on performance. Personality and Individual Differences. 2005; 39(4):693-703.

9. Boyatzis R, Goleman D, McKee A. Primal leadership: Realizing the power of emotional intelligence. Boston, MA: Harvard Business School Publishing. 2002.

10. Hadjali HR, Salimi M. An Investigation on the Effect of Organizational Citizenship Behaviors (OCB) Toward Customer-orientation: A Case of Nursing Home. Procedia-Social and Behavioral Sciences. 2012; 57:524-32.

11. Sadati SE. A survey relation of organizational culture and organizational citizenship behavior with employees' empowerment. Management Science Letters. 2012;2(6): 2175-2186.

12. Monfared SY, Mousavi SH, Sajjadi S, Heidary A. Assessing Organizational Citizenship behaviour Among Physical Education Teachers In Zanjan-Iran. Procedia-Social and Behavioral Sciences. 2011; 15: 3661-4.

13. Bove LL, Pervan SJ, Beatty SE, Shiu E. Service worker role in encouraging customer organizational citizenship behaviors. Journal of Business Research. 2009; 62(7):698-705.

14. Yildirim Y, Uzum H, Yildirim I. An Examination of Physical Education Teachers in Terms of their Organizational Citizenship Behaviors and Organizational Loyalty According to Some Demographic Variables. Procedia-Social and Behavioral Sciences. 2012; 47: 2146-56.

15. Mahdiuon R, Ghahramani M, Sharif AR. Explanation of organizational citizenship behavior with personality. Procedia-Social and Behavioral Sciences. 2010; 5: 178-84.

16. Willard S. Relationship of emotional intelligence and adherence to combination antiretroviral medications by individuals living with HIV disease. Journal of the Association of Nurses in AIDS Care. 2006; 17(2):16-26.

17. Refler S V. The effects of a leaders emotional intelligence on employees, trust in their leader and employee organizational citizenship behavior. Submitted to Regent University School of Leadership Studies In partial fulfillment of the Requirements for the Degree of Doctor of Philosophy in Organizational Leadership. 2004.

18. Korkmaz T, Arpac E. Relationship of organizational citizenship behavior with emotional intelligence. Procedia-Social and Behavioral Sciences. 2009; 1(1):2432-5.

19. Aghdasi S, Kiamanesh AR, Ebrahim AN. Emotional Intelligence and Organizational Commitment: Testing the Mediatory Role of Occupational Stress and Job Satisfaction. Procedia-Social and Behavioral Sciences. 2011; 29: 1965-76.

20. Guangling W. The study on relationship between employees' sense of organizational justice and organizational citizenship behavior in private enterprises. Energy Procedia. 2011; 5: 2030-4.

21. Jain AK, Cooper CL. Stress and organisational citizenship behaviours in Indian business 
process outsourcing organisations. IIMB Management Review. 2012; 24(3): 155-163.

22. Barriball L, Fitzpatrick J, Roberts J. Emotional intelligence: Its relationship to stress, coping, well-being and professional performance in nursing students. Nurse education today. 2011; 31(8): 855-60.

23. Jafari $\mathrm{P}$, Bidarian $\mathrm{S}$. The relationship between organizational justice and organizational citizenship behavior. Procedia-Social and Behavioral Sciences. 2012; 47: 1815-20.

24. Bradbury T, Graves J. Emotional intelligence (skills and tests). Translation: Mehdi Ganji. Tehran: Savalan; 2006.

25. R H, Naderi N. The study Level of Staff,s organizational citizenship behavior. Journal of executive management Scientific Research. 2009; 1(9):103 - 18.

26. Yazdani HR, Zare Mirakabadi A, Nasiri M H, Asad Nejad Mehdi. Investigating of Relationship Between Customer Orientation and Organization. Journal of Business Management Perspective. 2012 ; 10: 69 -53 [Persian].

27. Khalesi N, Ghaderi A, Khoshgam M, Borhani Nejad VR, Toroski M. The relationship between organizational citizenship behavior and empowerment in health centers, Tehran University of Medical Sciences. Journal of Health Management. 2011; 13 (42): 81 75[Persian].
28. Salarzehi H, Yaghoubi NM, Naroei M, Sin LG. A survey of relationship between emotional intelligence and organizational citizenship behavior in Iran. International Business and Management. 2011; 3(1):130-5.

29. Delpasand M, Nasiripoor AA, Raiisi P, Shahabi M. Relationship between emotional intelligence and occupational burnout among nurses in Critical Care Units. Iranian Journal of Critical Care Nursing. 2011; 4: 79-86.

30. Assadi MM, Nadafi Gh, Shafie Rudposhty M. Relationship between emotional intelligence and organizational citizenship behavior in public librarians (Case: Yazd city public libraries). Library and Information Science.2012; 14(1): 125-153[Persian].

31. James JK, Velayudhan A, Gayatridevi S. Organizational citizenship behavior and emotional intelligence of corporate executives. Journal of the Indian Academy of Applied Psychology. 2010; 36(2):262-7.

32. Hatam Gooya H, Anboohi Zahri S, Moghaddam M, Alavi Majd H, Tayebi Arasteh M. Evaluation of emotional intelligence and its relationship with demographic variables, in clinical nurses working in teaching hospitals of Kurdistan University of Medical Sciences in 2010. Scientific Journal of Kurdistan University of Medical Sciences.2012; 17(1):61 -71[Persian]. 